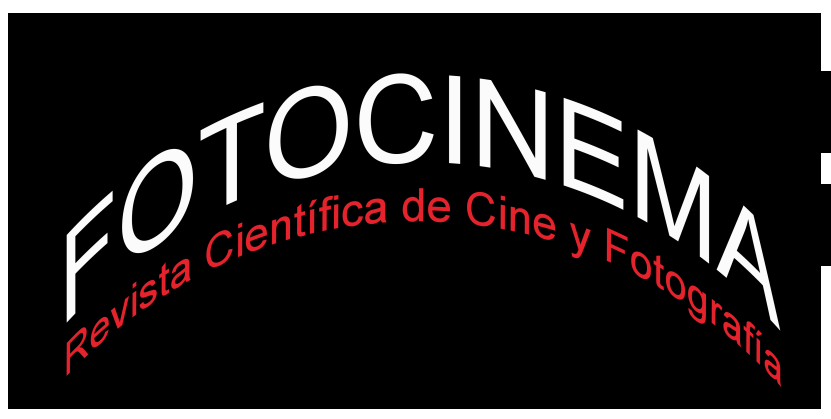

\title{
SOBRE LA FUNCIÓN LEGITIMADORA EN SOLAS (ZAMBRANO, 1999) Y LA GRAN FAMILIA ESPAÑOLA (SÁNCHEZ, 2013)
}

\section{ABOUT THE LEGITIMIZED FUNCTION IN SOLAS (ZAMBRANO, 1999) AND LA GRAN FAMILIA ESPAÑOLA (SÁNCHEZ, 2013)}

\author{
Eder García Dussan \\ Universidad de Bogotá, Colombia
}

\section{Resumen:}

El artículo expone las digresiones que motivan una lectura intertextual que se construye a partir de dos textos cinematográficos de factura española, y que toman como referente esencial la función del Padre o Padre de la Ley, tal como es trabajado desde el psicoanálisis, cuya función es la de legitimar un orden social. Para lograr este esfuerzo, nos apoyamos en un modelo lector inspirado en el Paradigma Indiciario. Los resultados de esta comprensión dejan ver cómo las circunstancias económicas y políticas de las naciones revelan que las dificultades en el cuerpo de la nación son el correlato de la crisis de quien encarna la Autoridad, la cual ha transmutado en otros rostros de legalidad como la figura de un Rey o la del deporte Rey (el fútbol). De esta forma, se concluye que el poder de El Padre, representante de la ley, ya no actúa ordenando la sociedad, sino desestructurándola, no sin antes dejar la ilusión de una cohesión, tan efímera como consoladora.

\begin{abstract}
:
This article exposes the digressions that drive us to a comprehensive reading of two Spanish films taking as essential element the role of 'the Father' or 'Father of the Law'as it is worked from psychoanalysis, which function is to legitimize a social order. To get to this goal, we will be supported by a reading model inspired in the Paradigma Indiciario. The results of this comprehension let us see how economic and political nations circumstances, reveal us that nations difficulties have a correlation with the crisis of who embodies the authority, which it has been transmuted into other faces of legality as the figure of a King or the King of sports (soccer). On this way, it is concluded that the power of The Father, the representative of the law, no longer acts ordering the society, but des-by structuring it, but not before leaving the illusion of a cohesion, as ephemeral as comforting.
\end{abstract}

\section{Palabras clave:}

Texto cinematográfico; logopatía; función legitimadora; Padre de la Ley; adbucción; indicio.

Keywords:

Film Text; Logopathy; Legitimizing Function; Father of the Law; Abduction; Index. 


\section{Introducción}

Una mirada atenta a las sociedades contemporáneas revela que estas se apoyan en el orbe iconosférico (Mosiváis, 2004), ligado a la dinámica mass mediática de la industria capitalista, esto es, a dinamismos simbólicos que no paran su marcha a pesar de que existen posturas apocalípticas que ven en ellos problemas significativos. En este contexto sociocultural, el texto cinematográfico toma su justo lugar en el concierto de las texturas que dan cuenta de la realidad social como un "arma" informativa (Virilio, 2006) usada para la producción casi fisiología de informaciones ocultas, o de su invisibilización. En esa medida, estas texturas se abran paso para convertirse en dispositivos de poder que expresan, enuncian, y/o pronuncian saberes, los cuales influyen en la vida de los ciudadanos. Dicho de otra forma:

En las sociedades contemporáneas el poder hace hablar, hace expresar a través de diferentes medios tecnológicos. Es necesario construir otros discursos, otras imágenes en la sociedad, pero también en la práctica pedagógica. El cine es así constitutivo de vacuolas que dan cuenta de lo no dicho (Osorio y Rodríguez, 2010, p. 71).

Visto así, el texto cinematográfico, muestra elementos culturales a partir de la representación di-simuladora de algunos aspectos históricamente relevantes, incluidos valores, creencias y conductas habituales de una sociedad (Delgado, 1999). Y, si bien es cierto que en el sistema textual cinematográfico algunos de sus signos integrantes se convierten en indicios gracias al orden y malicia de la cámara impuesta, también lo es el hecho que, por efectos de la identificación y/o la alteridad de lo mostrado y lo procesado por el auditorio, un receptor no puede dejar de entenderlos como símbolos de un mundo velado en la memoria social y actualizado en la materia del texto audiovisual a través de sus complejidades sígnicas.

En esa medida, la visión-versión del mundo que ofrecen los textos audiovisuales generan una realidad que se exhibe a través de una fusión potente de intenciones: anunciando (hacer saber), persuadiendo (hacer creer), maniobrando (hacer parecer verdad) y sobreexcitando (hacer sentir). 
Esto permite que los contenidos expuestos afecten al receptor haciendo que este, a partir de la experiencia estética, conceda una visión comprensiva del mundo (Cabrera, 1999). De este modo, un film no sólo muestra-la-realidadsocial, sino que ayuda a edificar formas puntuales de percepciones sociales, formas maleables de verdad histórica, pero también de actuaciones en y sobre ella, condicionando el saber compartido que se tiene de la vida social.

Es por eso que en el texto cinematográfico la razón entra en conformidad con la emoción, especialmente cuando ésta última adquiere una función cognitiva, cognoscitiva y persuasiva, por lo que es posible hablar, siguiendo de nuevo a Julio Cabrera, de la 'razón logopática', la cual atosiga pretensiones de verdad y de universalidad. Así, leer comprensivamente un texto audiovisual, leerlo desde el plano llamado "detrás de las líneas”, se convierte tanto en una práctica letrada inserta en ciertas prácticas sociales, como en un acto de desciframiento racional-emocional del mundo que moramos (Cassany, 2006).

A partir de este marco de entendimiento se procura, en adelante, tejer una lectura comprensiva a propósito de las formas de representación de la función legitimadora de la figura de autoridad (o su ausencia, o su sustitución), específicamente en dos películas españolas, caracterizadas por despertar hondas emociones en sus auditorios (miedo, enojo, resentimiento, amor) y que, por eso mismo, al existir una afectación, obligan a una especulación sobre su contenido latente y sobre el acervo de sentidos culturales presentes en el devenir colectivo allí plasmado. Estas películas son Solas (1999), del director andaluz Benito Zambrano, ganadora de cinco premios Goya, incluyendo mejor dirección novel y guion original; y La gran familia española (2013), del director madrileño Daniel Sánchez Arévalo, validada con diez nominaciones en la XXVIII edición de los Premios Goya al ser considerada la comedia más entretenida en los últimos lustros en España. De esta forma cubrimos no sólo dos géneros cinematográficos (drama y comedia, respectivamente), sino dos décadas de muestras sociales agenciadas por la magia del texto cinematográfico. Y, para lograrlo, debemos 
antes pasar por el entendimiento de qué es la función legitimadora y la figura del padre.

\section{Marco teórico: acerca de la función legitimadora}

Sabemos que la legitimación es la función por medio de la cual alguien, ordinariamente una autoridad o padre, busca los medios para que un colectivo acate voluntariamente unas leyes (Chilton y Schäffner, 2000). Ahora bien, quien encarna esta intención debe estar ubicado en un lugar institucional que le da la garantía para ejecutar tal acción de im-posición normativa; sólo así su discurso sostiene la veracidad y credibilidad de su representación (van Dijk y Martín Rojo, 1998). Bajo estas circunstancias, la re-producción discursiva del dominio y la veracidad sociales están basada en el concepto de poder, asociado directamente al de control social (van Dijk, 2004) y coligado también a algo que, en adelante, podemos llamar El Gran Padre, casilla significante que se ocupa con una figura de legitimación. Esto consiente aceptar que la función del Padre sea la de un ejercicio donde se controla el contexto físico, las estructuras y niveles de los textos y, finalmente, la vigilancia sobre la mente, receptáculo de memorias episódica y social, afectadas por ciertas estrategias como, por caso, la recreación acomodada de algunos aspectos informativos.

Ahora bien, la personificación de ese Gran Padre no es marmórea (de ahí su entendimiento como marca significante). Así por ejemplo, a finales del siglo $\mathrm{V}$, se impuso un dualismo gestado por Agustín de Hipona y San Ambrosio denominado la Doctrina de las Dos Espadas (utrumque gladium), que representaban el papa y el emperador o, lo que es igual, el gobierno de Dios y el régimen Civil, con supremacía del primero sobre el segundo (Sabine, 1980). Ya en la plenitud de la Modernidad, sus ideales filosóficos asignaron los preceptos del Iluminismo, haciendo que El Gran Padre fuese la razón encarnada en los padres de la Ilustración. Esto permitió que se estableciera una separación “[...] del mundo objetivo, creado por la razón, y del mundo de 
la subjetividad, centrado en la persona quien deja de lado todas las creencias y formas de organización que no se basen en elementos científicos" (Pourtois y Desmet, 2007, p. 25).

Ya en la Postmodernidad, etapa caracterizada por criticar la forma de entender la autoridad moderna para dejar entronada la falta de control, determina la irrupción de alternativas de control social en escenarios nuevos e irrepetibles, cualificados por su carácter perspectivístico y por la falta de certidumbres (Greco, 2007). Es así como, a finales del siglo XX, 'Postmodernidad' resulta ser sinónimo de 'crisis de racionalidad'; permitiendo los senderos de la razón y la recionalidad se conciban 'líquidos' (Bauman, 2004); obligando a que cada sujeto se haga cargo de su propio destino, lo cual permite el enlazamiento de lo privado a lo público, cuya primera consecuencia es la gestación de nuevos rostros de autoridad o nuevas versiones del Padre; meras pére-versiones ${ }^{1}$ que, de suyo, no quedan necesariamente ligadas a la coerción y la fuerza, puesto que

Esa autoridad del gesto y la palabra que instituyen, hoy parece estar amenazada, no ser reconocida, no apelar a un origen ni potar un saber trascendente. La autoridad no se desplaza hacia otro lugar, tiene dificultades para ser encarnada y reconocida [... en ese sentido] Sería, entonces, válido insistir en la búsqueda de nuevos modos de autoridad que establezcan un nuevo régimen de palabras y de acciones coherentes con nuestro tiempo (Greco, 2007, p. 55).

Ahora, partiendo de este devenir histórico occidental es posible pensar en una emancipación, por la vía de la emocionalidad. Esto es, frente a la crisis de la figura paterna emprendida en los albores de la Postmodernidad y jalonada por la sospecha, frente a esa "rebelión contra El Padre" (Mendel, 1975), que deja ver el agotamiento del modelo de la autoridad tradicional y la muerte de un principio de eficacia que ayudaba a sostener o anudar la figura paterna real; frente a toda esta crisis impuesta por la maquinaria social que

${ }^{1}$ La forma de interactuar frente al Otro se realiza en un espacio perverso, o mejor: Péreverso, puesto que se crea una nueva versión de la ley (= del Padre), en la que las cosas se acoplan a una nueva lógica. 
vuelve intolerable todo contacto con la autoridad y que despierta el terror y la violencia, aparecen nuevos retratos a quién engancharse en medio de la vacilación.

Así las cosas, la nueva figura paterna apunta a una naciente función del Padre que satisface directamente a las funciones de la ley². Todo esto es, para Horkheimer, consecuencia de una profundo aprieto centrado en la crisis del individuo burgués tras la naciente sociedad de masas y que manifiesta como "[1]a crisis de la razón manifestada en la crisis del individuo" (2002, p. 138). Para comprender esta tesis, basta con reconocer que, hasta bien entrado el siglo XIX, el núcleo familiar era el medio que prolongaba la rutina burguesa. En esta los niños percibían como relevante el poder apersonado y protector del padre, cuya imagen y prácticas servían como modelo hacia su adultez, y del cual recibían la empresa o la fortuna heredada y, con ella, el individualismo y el pensamiento independiente. La empresa misma, de la que se esperaba que continuara como herencia familiar, confería a las reflexiones del hombre de negocios una visión de futuro, lo que le permitía estar orgulloso de sí mismo y de su generación, persuadido de que la comunidad y el Estado descansaban en él y en

“[...] su convicción de que había que hacer justicia a las exigencias de un mundo de lucro se expresaban en un yo fuerte y al mismo tiempo lúcido y sereno, que imponía intereses que iban más allá de sus necesidades inmediatas" (Horkheimer, 2002, p. 149).

Sin embargo, la sociedad comienza a imponer el intercambio libre y la explotación capitalista, lo cual lleva a la ruina a la propiedad del burgués, transformando tanto la posición social, como la estructura psíquica de

\footnotetext{
${ }^{2}$ Recordemos aquí que para Freud, el niño sufre un proceso de socialización que tiene su lugar en la figura del Complejo de Edipo. El Padre, el rival, en un primer momento necesita ser superado en sus cualidades por el acceso a la madre; entonces, el niño al tener la simple intención de tomar el lugar del Padre frente a la madre realiza la introyección de la autoridad paterna, es decir, la asimila, introduciéndola en su propio yo. Es así como la estructura racional interiorizada prolonga una dependencia infantil y suplanta la forma real del Padretótem por la racionalidad de las normas morales del sistema de producción que se asienta sobre la persistencia, ahora fetichizada, del primero. Así, ya no es El Padre con el que medía cada acto de amor frente a su madre-fálica: es El Padre, la ley de las leyes, que se manifiesta de manera comprensible como código ordenador, penal (Freud, 1988).
} 
aquellas familias que otrora servían de amparo a los niños. A medida que la estructura tradicional de la familia se destruye gracias a la industrialización, la figura del Padre, atenuada por la voluntad de la madre, comienza a debilitarse; entonces, el niño comienza a interiorizar la imagen abstracta de un padre que no responde al ideal del yo, pues tales individuos ya no son señores del proceso de producción propio y no son ellos mismos hombres integrales, sino partes de una nueva organización social que se impone por encima de ellos sin que comprendan tal engranaje social.

Producido este fenómeno socio-económico, las normas ya no son incorporadas y elaboradas como antes, sino que prolongan una esclavitud que, para la mayoría de los hijos, es tan inconsciente como la propia esclavitud que los padres padecen, lo cual decanta en la producción de actores sociales incapaces de utilizar reflexivamente las normas que se transmiten mediante los contactos del Yo naciente con el mundo externo, progresivamente impregnado de poderes extra-familiares que circulan durante el largo período de dependencia del niño de sus padres; todo esto bajo el patrón consistente de influencias que se llevan por medio del proceso psíquico de la Identificación. Entonces, en lugar de los padres, aparecen sustitutos que imponen a los niños lo que ha de valer en el momento como ideal de la cultura. De esta suerte, El Padre cambia de fisonomía, se derrumba el Gran Padre y da paso a los padres.

Ahora bien, tras este rodeo, surge la cuestión de cómo se refleja esta mutación del Gran Padre, vital en la medida en que se percibe y condiciona la existencia social $\mathrm{y}$, por tanto histórica. Una posible vía de búsqueda y comprensión, se da, entonces, en la lectura atenta a los entresijos de los productos textuales culturales, como el texto cinematográfico pues, finalmente, la astucia de este tipo de textos es la de plasmar estructuras sociales en organizaciones semio-discursivas. 


\section{Metodología. Experimentos de lectura indicial}

Frente a la complejidad de textos cinematográficos, abundantes en mixturas de género, lógicas perceptivas, astucias comunicativas y contextos, resulta estratégico adoptar algunos parámetros disciplinares que favorezcan el tránsito de lo literal-inmediato a lo latente-inferencial, lo cual no sólo implica el conocimiento de sus texturas expresivas, sino el desarrollo de una actitud crítica ante el contenido ideológico de sus mensajes (Lomas, 2003). Para lograr ello, se asume un modelo que toma las texturas culturales y transforma sus reservas de significación socio-cultural a través de la generación de hipótesis explicativas de hechos textuales y que se propone guiar un acto lector a través de la ubicación de pistas que actúan como signos-indicios, centrados en algunas premisas del llamado Paradigma Indiciario. Para lograr esta meta, se tienen en cuenta algunos principios determinantes, tales como:

(i) Todo texto, con lo que dice, quiere decir algo más (el discurso se presenta como un iceberg; así, todo producto cultural se concibe en su doble naturaleza funcional).

(ii) Nadie enuncia nada desde la nada (el texto deviene discurso: está inscrito en coordenadas físicas, socio-históricas, socio-políticas, culturales $\mathrm{y}$ cognitivas).

(iii) Pese al principio anterior, el discurso no se limita a las determinciones contextuales (todo discurso es una obra abierta y atemporal; que captura, incluso, al propio lector, que nunca es el mismo en ninguna época).

(iv) el leedor es co-autor del discurso (el leedor llena vacíos, con-forma, reconfigura y completa y/o actualiza los contenidos de la forma textural con sus propios 'horizontes de sentido').

(v) Mientras se lee, el lector se enfrenta a una etapa de análisis o de tensión, que forja una labor intratextual donde se separan los diferentes componentes del texto y se examinan las propiedades y funciones en algunos niveles lingüísticos (V. gr. el léxico-semántico, el pragmático, etc.) buscando material 
indexical. Esta fase da origen a una segunda, la etapa de interpretación o de distensión, que genera un trabajo extra e intertextual donde se manipula la arquitectura indicial y se crean relaciones hasta lograr hipótesis de sentido sobre el querer decir del texto.

(vi) En el tránsito de la primera etapa a la final, la búsqueda de signosindicios es clave, y se puede guiar cuando se determinan hechos novedosos que irrumpen al lector "[...] obligando a buscar relaciones entre el o los eventos novedosos a partir de una regla general dada por la experiencia para, así, llegar a una abducción o hipótesis" (Otero y Correa, 2013, p. 307). La interpretación, entonces, es una operación que reduce el acto lector a una arte de la investigación y del trabajo intertextual, lo cual permite avanzar una traducción (Larrosa, 2003) del contenido latente al patente. El mismo Eco (1992) resume esto como un proceso inferencial, basado en la formulación de hipótesis, que se adelanta para explicar o desambiguar un suceso comunicativo concreto.

Pues bien, a partir del apoyo de estos elementos metódicos, se tratará, en adelante, de explotar algunos de estos aspectos para "traducir" los esquemas generales de narración que componen el corpus de textos cinematográficos objeto de atención en este esfuerzo, explotando hechos indiciales contendido en él, y que permitirán avanzar en la construcción de una hipótesis de sentido, pasando así del drama de Solas, a la comedia de La gran Familia española para evidenciar una posible relación, a propósito de la representación del Gran Padre, con comparaciones ofrecidas por otras obras cinematográficas que exponen el mismo tema.

\section{Ex-posición. Dos dramas distintos y ningún padre verdadero}

A pesar de que la película Solas (Zambrano, 1999) ha sido objeto de un número considerable de estudios previos, estos se centran en analizar mucho más en determinar cómo está representada la soledad y la distancia entre las generaciones y su materialización en los juegos de mirada desde 
sus mujeres protagonistas (Berger, 2008), en cómo la ópera prima de Zambrano propone elementos para pensar la España social del siglo XX (Regidor Resino, 2000), o en ser un paradigmático ejemplo de análisis de texto audiovisual a través de elementos constitutivos como el entorno, la luz, las acciones y diálogos de sus personajes, etc. (López, 2007). Pues bien, nuestro interés está centrado en analizar la figura paterna allí presente que descansa en el esposo de Rosa y padre de María, además de la figura del viejo vecino y su relación con otras obras cinematográficas iberoamericanas que despliegan claves similares a propósito de la figura paterna, haciendo de este esfuerzo una novedad frente los tratamientos investigativos anteriores.

Iniciamos el esfuerzo indicando que Solas muestra una historia simple y sobria que transcurre en el barrio marginal de San Bernardo, en Sevilla, sucesos que se desarrollan en algo más de una semana. Allí se ve cómo una analfabeta, provinciana y abnegada mujer, Rosa Jiménez Peña, acompaña a su marido quien, internado en un hospital de la ciudad, se recupera de una intervención quirúrgica. En los ratos en que no está custodiando a su esposo, reposa en la casa de su hija María, mujer de unos treinta y cinco años que sobrevive, sin esperanza y sin un futuro definido, trabajando como empleada en una empresa de aseo y que apadrina como compañía preferida el licor. El desarrollo de la historia pronto delata que María está embarazada.

Entre tanto, El Padre de María y esposo de Rosa (nunca sabemos su nombre), pese a estar convaleciente en una cama, es modelo de un hombre autoritario, dominante, opresor, celoso e intransigente, cualidades reforzadas por el conocimiento de su adicción al juego y el alcohol. Este perfil se confina en un machismo extremo, manifestado abiertamente en una interacción verbal con Rosa en el cuarto día de acciones del film y que sucede cuano le pide a Rosa que se acerque y, tras preguntarle dónde estaba, le dice con pesadez y antipatía: "hueles a macho", acto con el cual le genera culpas y conductas malsanas a su cónyuge. En cuanto a la pareja de 
María, se trata de un camionero, casado y narciso que rehúsa aceptar su rol paterno ante la noticia del embarazo. María queda, entonces, afrontando sola su situación, bajo la mirada silenciosa de su madre visitante.

Ahora bien, en esta visión de estructura familiar, vemos cómo Rosa representa, ante todo, los valores femíneos de una sociedad patriarcal (resignada, servicial y sumisa), razón por la cual sostiene la figura autoritaria del esposo; mientras María, quien aparece cualificada como su antítesis, representa la desconfianza en el otro-diferente, empezando por su rudo padre y, cuando tiene la oportunidad, reprocha a su madre el no haber sido capaz de desembarazarse de la tiranía de su marido y de su condición premoderna. No obstante, tal como afirman Puebla, Díaz-Maroto y Carrillo, las dos, en esencia, son harina del mismo costal:

Rosa y María representan así las dos caras de la misma moneda. Dos mujeres abandonadas y sometidas por el hecho de ser mujeres, aunque cada una hace frente a ese hecho de distinta forma: Rosa se resigna y sonríe para sí misma - sonríe aunque su marido la insulte y sonríe ante los gritos de su hija-, María, en cambio, se enfada con el mundo y llora y bebe hasta emborracharse y olvidarse de todo. Las dos mujeres nos acercan a las diferencias en la condición del ser humano por el hecho de pertenecer a un sexo u otro, o por pertenecer a generaciones distintas, o por pertenecer a dos mundos distintos, aunque en realidad ambas no se diferencian en casi nada (2013, p. 149).

Ahora bien, si desviamos la mirada de ellas, y el del triángulo familiar que delinean, este cuadro se completa con la presencia de un vecino viejo, "el asturiano", quien aparece acompañado de su perro Aquiles (lo que recuerda, sin más, un héroe de guerra), y quien, sabemos, sirve de padre putativo para María. Es así como el viejo, tras la partida de la madre a su terruño originario, invita a cenar a María y, después de una belicosa disputa verbal, la persuade para adoptar como abuelo a su hijo, y a ella como nieta3.

3 Interesante resulta ver cómo esa forma primigenia de interactuar entre "el asturiano" y María se da simbólicamente en un juego de cartas, como cuando se dice coloquialmente: "poner las cartas sobre la mesa" para querer decir que se desea "hablar sin tapujos sobre un espinoso asunto". 
De esta suerte, coincidimos con las apreciaciones de Puebla, Et. Al. cuando afirman que "[...] a partir del día a día de estas mujeres, Zambrano denuncia situaciones de soledad, desamparo, incomunicación o injusticia. Todas ellas son mujeres con vidas difíciles debido a circunstancias de las que muchas veces ellas no son responsables" (Puebla, Díaz-Maroto y Carrillo, 2013, p. 163). Empero, la luz matutina de esa noche de querella entre el viejo y María deja entrever la esperanza para la solitaria y desamparada mujer en cinta. Ya en el clímax del film se muestra un nuevo triángulo familiar (el asturiano, María y su retoño), visitando el nicho final de los padres de María, y la voz en off de ésta es la introducción de una relación que mantendrá con su difunta madre, como si la complicidad entre ellas fuera posible solamente en ausencia de Rosa.

Pues bien, enmarcado así el asunto, estamos ante una experiencia estética que representa familia doliente y disgregada, afectada por la posguerra española (Lanuza, 2012), matizada por elementos de la política represiva y anti-democrática del falangismo 4 . A su vez, la penuria social y económica de María embarazada simboliza, así, una nación (la madre patria) ilustrada en un férreo dominio autoritario del cual desea separarse abruptamente para apadrinar, desde lo marginal de su postura, otra figura de legitimidad, esta vez representada por el anciano quien, no gratuitamente, apodan "el asturiano", ya que esta marca indexical del texto audiovisual evoca rápidamente al Príncipe de Asturias, Juan Carlos I de España, proclamado rey de España el 22 de noviembre de 1975, tras la muerte del dictador Francisco Franco. Y, sabido es que la figura del Rey de España, encarnada en un sujeto históricamente determinado, ha sido reconocido por cumplir un papel de apoyo fundamental en la llamada Transición Española (1975-1982), período histórico durante el cual se llevó a cabo el proceso por el

4 El falangismo es la versión española del fascismo que se formó bajo la influencia italiana y alemana a comienzos de los años 30 del siglo XX como reacción a la tendencia socializante de la Segunda República Española. Después de la Guerra Civil (1936-1939), con la dictadura del general Francisco Franco (1892-1975), el falangismo llegó al poder y se mantuvo durante la larga dominación franquista en España, y sus líneas ideológicas fundamentales estuvieron centradas en un concepto de España como unidad de destino; desaparición de los partidos políticos y protección oficial de la tradición religiosa católica española. 
que España dejó atrás el régimen dictatorial y pasó a ser un estado social y democrático de Derecho.

Somos conscientes que la manifestación histórica del Padre, sus efectos en la conciencia nacional y su actual forma de ser evocado o reconocido en el cine contemporáneo es tan extenso y tan finamente que sería difícil precisar un conjunto de ejemplos modélicos. Sin embargo, nos resulta cómodo poner a dialogar Solas con El laberinto del Fauno (2006) del director Guillermo del Toro, donde la figura del Padre está cifrada en el personaje del fascista Capitán Vidal, quien también desea fungir de padrastro de la chica Ofelia y cuya función en el ámbito rural es enfrentar a muerte guerrilleros republicanos. El reloj del Capitán, símbolo del fascismo y que acompaña las soledades nocturnas del Capitán (Enjuto, 2009), es realmente una herencia de su padre y le sirve al hijo para evocar la valentía militar de su progenitor; esto es, representa, sin más, la masculinidad férrea que se encapricha con eliminar al enemigo y concebir una muerte honrosa para mantener viva la Ley; a tal punto que ya se ha hecho leyenda entre el mundo militar de la época. Lo curioso es que ese reloj está detenido y quebrado; esto es, la materialidad del símbolo está añosa y es disfuncional. Además, ante la mirada de los aliados, Vidal niega el simbolismo legendario del objeto, abandonando así ante el otro el legado de su padre y lo que él representa como mediador del nuevo Estado-nación. De esta suerte, el Proto-padre no sólo queda elidido, sino sin la posibilidad de que su encarnación siga su legado en la nueva generación, el hijo de Vidal, quien no sólo quedará sin el reloj-símbolo, sino también sin saber nada del brioso carácter de su padre. Al final, son los seres fantásticos (como el fauno) quienes, de manera muy sutil, vienen a encarnar la figura de poder, mediados por la candidez y el arrojo infantil.

Ahora, lejos de creer que esto es un asunto local, creemos ver el derrumbamiento de la figura de autoridad en aquellas naciones que, acompañadas de grandes proyectos hegemónicos nacionalistas y sus invenciones de ciudadanía, han intentado erigirse con autonomía nacional a 
partir de emblemáticos padres, estrategias de la Polis, y no de la Urbs ${ }^{5}$, y que se han personificado en mitos centrados en un héroe. Así, el caso de Colombia donde, desde su proceso independentista, ha venido empadronando "la gloria y el patrioterismo militar" (Hobsbawn, 2009 p. 331) con mitos legendarios tales como el del libertador de cinco naciones (Simón Bolívar) o el mito del hombre de las leyes (Francisco de Paula Santander), casi siempre materializados en estatuas ecuestres y que se han actualizado con la misma lógica significante.

Pues bien, en el último lustro muchas películas han intentado dar cuenta de cómo ese Padre, el Estado-nación y sus mitos, es un débil tótem que se reemplaza por la ley personal. Verbi gracia, en la cinta colombiana Retratos en un mar de mentiras (2010), del director Carlos Gaviria, reconocida con el Premio Ciudad de Venecia en 2011, los protagonistas se desplazan de la zona marginada de la ciudad de Bogotá hacia un extremo secundario de la costa atlántica en un desvencijado Renault 4, con el ánimo de reclamar las tierras arrebatadas por los paramilitares cuando uno de ellos, Marina (nombre significativo, pues evoca a la esposa del conquistador español) era una niña. Este Film, Road Movie, muestra entronizado al presidente de la época, Álvaro Uribe, al tiempo que revela cómo la Ley que impone el Estado no opera con equidad sino, más bien, genera injusticias sociales con mentiras y trapisondas. Entonces, la Ley del Estado-Padre es reemplazada por la ley del Padre Corrupto (Díaz, 2000); esto es, el que encarna en el usurpador y avivato para maniobrar amparado en su ley, distorsionando el bien común y la armonía social. De esta manera, el film es es la representación de la Colombia que ha vivido en constante agitación sociopolítica por más de sesenta años, una guerra civil que ha dejado a más de cuatro millones de

\footnotetext{
5 En efecto, el antropólogo Manuel Delgado Ruiz (Institut Català d' Antropologia) propone un modelo antropológico sobre las culturas modernas que diferencian entre Urbs y Polis. La Urbs estaría constituida por un dinamismo hecho de fragmentos en contacto, espacios colectivos produciéndose, un constante hacerse como formas urbanas territorializadas, contrario a una autoridad fiscalizadora, patria exaltada y controlada por manipulaciones políticas a través de operaciones macro-semióticas como la redención del espacio social (1999b, pp. 30 y ss.).
} 
desplazados, y cuyo antecedente fue más de once constituciones políticas y más de sesenta revueltas sangrientas, muestra de que El Gran Padre en Colombia es tan perecedero y precario, como las leyes que pro-pone sin imponer.

De esta manera, se evidencia la tendencia de las naciones a encontrar 'nuevos modos de autoridad'; un cambio en el rostro del Padre y su función legitimadora que, en este caso, pasa del aspecto pétreo, bestial y divinizado del generalísimo Franco o de ciertos presidentes latinoamericanos; cambalache que muta en el rostro del subalterno de una micro-dictadura social anclada en el pasado aldeano español (Berrocal, 2008) para el caso de Solas, o en el rostro del villano paramilitar, auspiciado por la precariedad del orden legal en la vida periurbana, para el caso de Retratos en un mar de mentiras.

En Solas ese rostro es el del compasivo viejo (el Rey), lo que implica una renuncia tanto al autoritarismo, como a la negación de la otredad; pero también es una dimisión a los efectos de la regresión económica y a la involución de la estructura familiar del sector agrario, tal como el film de Zambrano deja ver todo el tiempo al hacer notar las diferencias entre la vida rural y urbana puesta metonímicamente en Rosa (representante de la vida rural) y María (representante del a vida urbana). Asimismo, este cambio de rostro de la autoridad permite anhelar un cambio en el ambiente familiar, bellamente metaforizado en la película cuando Rosa, tras su intervención amorosa, embellece la morada, transformando el piso oscuro, desordenado, sucio y húmedo con el que se encontró.

Ahora bien, en relación con La gran familia española (Sánchez Arévalo, 2013), este film desarrolla también una historia escueta: durante la final del mundial de fútbol de Sudáfrica, se celebra una boda entre dos jóvenes que no sobrepasan los dieciocho años de edad: Carla, supuestamente encinta, y Efraím, su novio de toda la vida. Esto sucede, asimismo, en una finca marginada de la ciudad. Con prontitud se nota que se trata de una familia desestructurada. Efraím tiene cuatro hermanos: Adán, el mayor, que se 
siente sub-valorado por su padre y eso lo mantiene acomplejado; Caleb, que es responsable y lleva mucho tiempo alejado de la familia trabajando como médico en el Tercer Mundo para una ONG; Daniel, que ha vivido siempre a la sombra de Caleb y quien, tras la llegada de este, siente celos por la creencia que le pueda arrebatar su actual enamorada; y, finalmente, Benjamín, un discapacitado intelectual, aparentemente ingenuo.

Este panorama de la estructura familiar, lo completa la madre, Carmen, ausente todo el tiempo en las acciones del film; sólo sabemos de ella por el relato final de Caleb: una mujer quien, después de soportar su propia desgracia, traiciona el propósito de la familia. Al lado de esta abultada familia aparece un trío de mujeres (Carla, Mónica y Cristina) que se caracterizan por ser causa de angustia, desasosiego, depresión, conflictos internos, rivalidad y peleas entre los hermanos de la Gran Familia. Finalmente, notamos que El Padre está cualificado como aquel que no ha superado su pasado tormentoso, concentrado en la desunión con el objeto de deseo, aquí solamente rememorado.

Constituida de esta manera la Gran Familia, vemos como El Padre de esta historia sufre, durante la boda, un infarto como efecto de su depresión causada por la crisis familiar. Estos personajes están acompañados por los invitados a la boda, un colectivo visible por estar pendientes de las pantallas para seguir el transcurso del encuentro futbolero entre las Selecciones de España y Holanda, en el marco de la final del Mundial de fútbol. Advertimos, además que la figura del Padre está diezmada, no sólo por el hecho de estar padeciendo los efectos de un problema cardiaco, sino por no haber podido cumplir el deseo de mantenerse unido a su esposa, lo que lo hace un patriarca que vive aferrado a un amor ya culminado; incluso, su imagen es débil (y hasta patética, si se quiere) por el hecho de no comprender que su esposa, al alejarse, ha hecho un sacrificio y un verdadero acto de amor.

Así las cosas, es claro cómo El Padre de la familia -española-, metonimia de las familias, aparece como un individuo emocionalmente torpe y poco competente para mantener la unión y la satisfacción personal de sus hijos tal 
como, efectivamente, se demuestra con las historias de Adán, Caleb, Daniel y Efraím. Incluso, Cris, la novia de dos de sus hijos, le cuestiona "¿No estás preparado para ver a Carmen? No tienes ninguna intención de superarlo", a lo que él responde: "No, porque un amor de verdad nunca se supera", con lo cual se entiende que ese Padre no posee los dispositivos que aseguren el bienestar de su nicho.

En esa medida, se puede entrever que El Padre bonachón y romántico, y que pensó como norte para su linaje el mismo sino de Siete novias para siete hermanos (Donen, 1954), no impone la ley; su función simbólica no es funcional y, en su derrotero frustrado, abre las brechas para los aprietos en la gran familia española. Y, aquí, lo curioso, en su lecho de enfermo, al igual que con El Padre de la película de Zambrano, aparece veladamente el interino que sí ofrenda una esperanza al colectivo frente a la situación enclenque de la familia; ya no un viejo-Rey, sino el deporte-Rey, el fútbol. Digámoslo de otra forma: la expectativa de una victoria de la selección española de fútbol se ancla en la familia y sus invitados para infundir expectación y hacer ver que las ilusiones se cumplen, y que sólo por eso merece la pena alimentarlas, buscando de paso la construcción efímera de una identidad social y un destino común y solidario.

Este recurso de tomar el deporte-rey como ícono de identidad y de ilusiones colectivas para la re-construcción identitaria nacional en ambientes donde la tensión política muestra cómo hay otras figuras de autoridad que emergen frente a la crisis de la autoridad del Estado-nación ha sido explotado muchas veces en el cine iberoamericano. Por ejemplo, la película colombiana La pena máxima (2001), del director Jorge Echeverry, muestra cómo la pasión que tiene el protagonista por la Selección colombiana de fútbol, lo lleva a empeñar su ya insignificante patrimonio económico y sus sueños de un mejor porvenir, pues el único móvil de su vida es asistir al partido de la Selección en unas eliminatorias clasificatorias a un mundial de fútbol. Es tanta la idolatría que manifiesta el protagonista por el fútbol, que pasa por encima de los proyectos matrimoniales e irrespeta el funeral de su tío. Al final, queda sólo, 
pero acogido por la ilusión que ese Gran Padre deportivo le promete para permitirse seguir su camino, ahora sin trabajo y sin esposa y con la repulsión de su familia. Y, en ese sentido, armoniza muy bien con la temática de $L a$ gran familia española.

En este mismo sentido, pero con una agregado especial, el de la cualidad efímera hasta del fútbol como nuevo rostro del Padre, se encuentra en la película mexicana Rudo y cursi (2008), del director Carlos Cuarón, otra comedia que enfrenta, esta vez, los hermanos Beto y Tato, por la obtención del poder totémico que otorga ser una estrella de fútbol. Ellos, obnubilados por haber salido de su espacio marginal, pasan incluso por la relación de hermandad para gozar de los beneficios que ofrece el deporte-rey, hasta el punto que se juegan sus destinos, esperanzas y limitaciones en un partido de fútbol en el que se desafían. Lo interesante es que, al final, ni siquiera el fútbol les sirve de sostén para mantener sus ilusiones de progreso y unidad familiar. Tato, alias "Cursi" termina siendo el tendero de un bar, propiedad de un narcotraficante, y las extremidades inferiores de su hermano quedan lisiadas. Así, al final, el Padre termina siendo el narco, el capo. Esta misma lógica temática se presenta en el film venezolano Hermano (2010), ópera prima de Rasquin, donde se repite el mismo fondo histórico que en la cinta mexicana, a saber: la ausencia de una figura paterna, la cual es reemplazada someramente por un capo visible en el ambiente violento de la comuna urbana; por cierto, un espacio igualmente marginal. En él, aparecen dos hermanos unidos por el deseo de que la macro-ficción del fútbol les satisfaga sus deseos y expectativas; además de que les subsane sus deudas materiales y simbólicas; en la etapa conclusiva, se desgaja la misma sospecha: el fútbol no hilvana el poder didactista de unión, felicidad e identidad; desacreditando, así, la idea de que ejercer un deporte es hacer madre patria.

En ese orden de ideas, las tres cintas revelan cómo El Padre débil es reemplazado por el deporte-rey, pero también desgajan la idea de que es un evento transitorio pues, finalmente, crea un "universo marginal fuera de la realidad" (Nuño, 1994, p. 7). De esta manera, podemos pensar que la 
espontaneidad y fortaleza que no encuentra una nación en la figura del Padre real, bien sea en el núcleo familiar o estatal, permite la eclosión de una exploración identitaria en funciones colectivas construidas artificial y efímeramente por la cultura -de masas-. Visión, por cierto, corroborada otrora por el sociólogo alemán Max Horkheimer cuando afirmaba contundentemente que:

(...) la debilidad del Padre, socialmente, condicionada, y no compensada por sus explosiones ocasionales de masculinidad, impide que el niño se identifique realmente con él. En épocas anteriores la base de la autonomía moral del individuo era la imitación amorosa del Padre seguro de sí mismo (...) Hoy El Padre tiende a reemplazarse directamente por entidades colectivas: la escuela, el equipo deportivo, el club, el estado. Cuanto más se reduce la dependencia familiar a una simple función psicológica, más abstracta y general resulta en la mente del adolescente; lleva así de modo gradual, a aceptar con facilidad toda forma de autoridad, mientras sea lo bastante viril (1986, pp. 184-185) . $^{6}$

Es así como el fenómeno de identificación en el fútbol parece responder a condiciones vigentes en el mundo de la época de la sociedad actual, cuando los modos tradicionales de lograr identidad individual a través de las relaciones familiares han entrado en apuros. Merecidamente, en este contexto social, se puede comprender que los fenómenos en torno a los deportes asignados como ícono de Estado-nación y, en especial al fútbol, donde lo festivo se combina con una est/ética de la solidaridad, se protegen gracias a un papel religioso para impulsar la fusión comunitaria e imponer una identidad multi-dimensional; pero también es una salida simbólica que sutura los efectos del estado de un país; por caso, de la enorme familia española.

${ }^{6}$ Sabemos que el sujeto adquiere su autonomía, su mayoría de edad, a través del mecanismo psíquico de la identificación con la autoridad (padre, amigo, hermano, héroe etc.), siguiendo un proceso de superación/conservación; tal como lo expresa el profesor Becker: “(...) Creo importante que mantengamos presente el que naturalmente el proceso de separación respecto de esa autoridad es necesario, pero que el hallar una identidad no es de otra parte posible sin el encuentro con la autoridad" (Adorno y Becker, 1986, pp. 43). 
Adelantada la lectura indicial de las dos texturas españolas tratadas, y sus diálogos o trabajo intertextual con otras películas iberoamericanas, creemos ver que sobresale de forma atractiva una relación en el orbe semánticopragmático de los dos productos: Solas y La gran familia española son películas filmadas en espacios marginales como una apuesta discursiva que expone la des-estructuración de la familia en relación con la función paterna, que atestigua su frágil función a propósito del compromiso frente a la Ley y a la organización social. De hecho, en los dos casos se evidencia que este evento está causado por un agotamiento emocional que impide la unión y armonía en el colectivo. Asimismo, las historias familiares desplegadas en las dos películas están atravesadas por el advenimiento de un nuevo Padre de la Ley que arrastra consigo herencias del pasado, restos de tiranías y de excesos de legitimidad, revelando, asimismo, una salida frente al asunto, al generar una perversión de la Ley (pére-versión), esto es, del Padre, a saber: el Rey o el deporte Rey, estampa social pujante pero perecedera.

También deseamos subrayar cómo las dos películas son gestadas y rodadas en momentos sociales críticos de la reciente historia española. El caso de Solas, de Zambrano, fue filmada a finales de la década de 1990, época en la que se hablaba del 'Milagro Español', expresión que reconocía el esfuerzo nacional de invertir en los fondos de cohesión europea; no obstante, esta acción contrastaba con un deterioro de la calidad de vida de sus ciudadanos; de suerte que la bonanza colectiva se daba gracias a una precariedad laboral que despertaba en la población una sensación de abandono por parte del Estado. Todo esto estaba evidenciado en el abaratamiento en los contratos laborales y el despido libre, lo que disparaba el miedo a perder el trabajo, pese a ser tan infructífero económicamente (Valero, 1999). De suerte que se vivía una pobreza no condicionada por la falta de trabajo, sino por su propia precariedad que, como en la metáfora de María, se traducía en una labilidad emocional y la de Rosa, en una fragilidad de autonomía. Cuestión esta recreada años después, en la película Los lunes al sol (2002), del director Fernando León de Aranoa, donde se desarrollan los efectos de la precariedad 
laboral española en un grupo de amigos, meras larvas humanas frustradas tras su despido, y causada por la reconversión industrial de la década de 1980.

En el caso de La gran familia española, esta fue filmada a comienzos de la década de 2010, justamente cuando el pueblo español sufría directamente los efectos de la llamada "segunda recesión de la crisis económica", y que para los países desarrollados significó la peor etapa económica desde la Gran Depresión de los años 30 en EEUU. En el caso de España supuso, desde finales de 2007, aprietos como el final de la burbuja inmobiliaria, la crisis bancaria y la corrupción política. Como consecuencia de esto, se comenzó a encumbrar la disminución del crédito a familias y empresarios por parte de los bancos, las cajas de ahorros y, en oposición a esto, se vivió el aumento del desempleo en las capas sociales media y baja, lo que puso en jaque la democracia establecida (Ortega y Pascual-Ramsay, 2012). Quizá lo más devastador de esta crisis ha sido la destrucción laboral que pone de manifiesto una nación que se enfrenta un peregrinaje económico. Cuestión, por cierto, cercana a la situación socioeconómica de países como Colombia o Venezuela, donde las tasas de desempleo son elevadas, permitiendo el paso al trabajo informal, a la figura del buhonero; pero, también, a unas violencias y percepciones de inseguridad tan marcadas que terminan por generar la convicción de un desamparo por parte de quien representa la Ley, con la consecuente eclosión de las leyes (pére-versiones), dejando, de esta suerte, abierta la herida en el orbe simbólico de las naciones.

\section{Cadarzo. A manera de cierre}

Así, pues, el ambiente sociocultural de España en los últimos cuatro lustros y en otros países en América muestra un Gran Padre cuya imagen ha acuñado un poder arbitrario que ya no ofrece un orden social armónico ni sostiene decorosamente las obligaciones que ellos deseaban explicitar a los miembros del cuerpo social, razón por la cual han venido permitiendo que se malgaste 
la exigencia, el ser de un deber. Así, pues, ese 'edificio derrumbado' se revela ante los analistas como la búsqueda colectiva de un Padre débil encarnado en un Padre Colectivo (Eros efímero) o un Padre Corrupto (Tanatos enmascarado); de la misma forma como ha sucedido con muchas federaciones de fútbol en el último año y hasta con la misma Federación Internacional de Fútbol Asociado (FIFA), donde las trapisondas y tramoyas con lo ilegal operan ahora ante los ojos del mundo entero, y que quedan resumidas en significantes como ‘soborno' o 'fraude'.

Para terminar, confirmamos dos elementos que tienen que ver con la dimensión de la formación lectora desde el auxilio del análisis del texto cinematográfico, a saber: por un lado, el entendimiento de que leer es traducir material textual indicial, aquí centrado en las dimensiones actanciales (El Padre, la madre, el hijo, los hermanos, el corrupto) y cronotópicas (últimos lustros, espacios marginales), que ha permitido hacer relaciones entre eventos del texto audiovisual a partir de experiencia socioculturales para, así, llegar a hipótesis que, incluso, permiten generar relaciones con contextos más locales y; por otro lado, la convicción de que, con el pretexto de reflejar lo real, el texto audiovisual se nos presenta como un baúl de finísimas relaciones semántico-pragmáticas, que contiene conocimientos de la realidad social, proponiendo maneras de interpretar el mundo y lo que en él acontece.

\section{Referencias bibliográficas}

Adorno, Th. \& Becker, H. (1986). Educación para la mayoría de edad. Revista Argumentos, 14-17, 54-60.

Bauman, Z. (2004). Modernidad líquida. Buenos Aires: Fondo de Cultura Económica

Berger, V. (2008) "La soledad a través de la cámara: "Solas" (1999) de Benito Zambrano", en Foro hispánico: revista hispánica de Flandes y Holanda, $\mathrm{N}^{\circ} .32$, pp.165-178.

Berrocal, J. (2008). La Huella Psicológica del Franquismo en el Cine Español de los Noventa. En Working Papers in Romance Languages, vól 1, Issue I, Article 2. Berkeley: Berkeley Electronic Press. 
http://repository.upenn.edu/wproml/vol1/iss1/2. Consultado el 23 de abril de 2015.

Cabrera, J. (1999). Cine: cine años de filosofía. Barcelona: Gedisa.

Cassany, D. (2006). Tras las líneas. Sobre la lectura contemporánea. Barcelona: Anagrama.

Chilton, P. \& Schäffner, C. (2000). Discurso y política. En T. Van Dijk (Comp.) El discurso como interacción social. Estudios sobre el discurso II (pp. 297-329). Barcelona: Gedisa.

Delgado, M. (1999). Cine. En M. Buxó, J. de Miguel (Eds.) De la investigación audiovisual: fotografía, cine, vídeo, televisión (pp. 4977). Barcelona: Proyecto A, ediciones.

Delgado, M. (1999b) El animal público. Barcelona: Anagrama.

Díaz, C. L. (2000). En torno al síntoma y al padre. Revista Colombiana de Psicología, 8, 11-22.

Donen, S. (1954) Siete novias para siete hermanos. Estados Unidos: MetroGoldwyn-Mayer

Eco, U. (1992). Los límites de la interpretación. Barcelona: Lumen.

Enjuto, C. (2006). La guerra civil española: entre fantasmas, faunos y hadas. En vanderbilte-journal of luso-Hipanic studies, vol 5 . Disponible en: http://ejournals.library.vanderbilt.edu/index.php/lusohispanic/articl e/view/3237/1452. Consultado el 10 de mayo de 2015.

Freud, S. (1988). El Malestar en la cultura. Madrid: Alianza editorial.

Greco, M. (2007). La autoridad (pedagógica) en cuestión. Una crítica al concepto de autoridad en tiempos de transformación. Rosario: Homo sapiens.

Horkeimer, M. (2001). Autoridad y familia (y otros escritos). Barcelona: Paidós.

Horkheimer, M. (2002). Crítica de la razón instrumental. Madrid: Trotta.

Hobsbawn, E. (2009) "Nacionalismo y nacionalidad en América Latina". En: Sandoval, P. (Comp.) Repensando la subalternidad. Miradas críticas desde/sobre América Latina. Perú: Instituto de Estudios Peruanos. pp. 327-344.

Lanuza, A. (2012). Cine, mujer y cambio social: el lenguaje audiovisual de la democracia a través de la película Solas. En J. Gonzálvez \& F. Cabezuelo (Coords.) La imagen del franquismo a través de la séptima arte: cine, Franco y posguerra. Madrid: Visión, libros. pp. 67-84

Larrosa, J. (2003). La experiencia de la lectura. Estudios sobre literatura y formación. México: F.C.E. 
Lomas, C. (2003). Textos y contextos de la persuasión Los medios de comunicación de masas y la construcción social del conocimiento. D. Bogoya (Ed.) Trazas y miradas. Evaluación y competencias (pp. 87101). Bogota: Editorial Unibiblos, Universidad Nacional de Colombia.

López, Á. (2007) "Análisis del documento fílmico. (Un ejemplo ilustrativo: Solas)", en Frame: revista de cine de la Biblioteca de la Facultad de Comunicación, $\mathrm{N}^{\mathrm{o}}$. 1, pp. 20-58

Mendel G. (1975). La rebelión contra El Padre. Barcelona: Península.

Monsiváis, C. (2004). Lectura y globalización. Elogio (innecesario) de los libros. Revista Número, edición 41, 9-15.

Nuño, J. (1994). Razón y pasión del fútbol. Revista Universidad de Antioquia, No. 236. pp. 4-12

Ortega, A. \& Pascual-Ramsay, Á. (2012). ¿Qué nos ha pasado? El fallo de un país. Madrid: Galaxia Gutemberg-Círculo de Lectores.

Osorio, A. \& Rodríguez, V. (2010). Cine y pedagogía: reflexiones a propósito de la formación de maestros. Revista Praxis \& Saber, 1(2), 67-86

Otero, L. \& Correa, M. (2013). La escritura de relatos policíacos: un escenario para la recursividad y la adbucción. Revista Lenguaje, 41(2), 303-324.

Pourtois, J. \& Desmetm H. (2007). La educación posmoderna. Madrid: Editorial popular.

Puebla, B., Díaz-Maroto, Z y Carrillo, E. (2013) "Los personajes femeninos bajo la mirada del cineasta BenitoZambrano", en Fotocinema. Revista Científica de Cine y Fotografía No 7 , pp. 137-167

Regidor, M. (2000) "Solas", escrita y dirigida por Benito Zambrano (1999)", en distancia, $\mathrm{N}^{0} 1$, pp. 263-265

Sabine, G. (1980). Historia de la teoría política. México: Fondo de Cultura Económica

Valero, T. (1999) Solas. Disponible: http://www.cinehistoria.com/solas.pdf

Van Dijk, T. (2004). Discurso y dominación. Grandes conferencias en la Facultad de Ciencias Humanas No.4. Bogotá: Universidad Nacional de Colombia.

Van Dijk, T. \& Martín Rojo, L. (1998). Había un problema y se ha solucionado: la legitimación de la expulsión de inmigrantes 'ilegales' en el discurso parlamentario español. En L. Martín Rojo \& R. Whittaker (Eds.) Poder-decir o el poder de los discursos (pp. 169234). Madrid: Arrecife.

Virilio, P. (2006). Ciudad pánico. El afuera comienza aquí. Buenos Aires: Libros del Zorzal. 


\section{Filmografía}

Cuarón, C. (2008) Rudo y cursi. México: Cha Cha Cha films y Canana Films.

Del Toro, G. (2006) El laberinto del Fauno. España: Tequila Gang, Esperanto Filmoj, Estudios Picasso, Sententia Entertaintment, Telecinco y OMM productions.

Donen, S. (1954) Siete novias para siete hermanos. Estados Unidos: MetroGoldwyn-Mayer.

Echeverry, J. (2001) La pena máxima. Colombia: Dago García Producciones Ltda / Canal Caracol Televisión.

Gaviria, C. (2010) Retratos en un mar de mentiras. Colombia: Producciones Erwin Goggel

León de Araona, F. (2002) Los lunes al sol. España: Coproducción EspañaItalia-Francia; Elías Querejeta / Mediapro / Eyescreen / Quo Vadis Cinéma.

Rasquín, M. (2010) Hermano. Venezuela: A\&B producciones.

Sánchez, D. (2013) La gran familia española. España: Atípica Films/Mod Producciones/Antena3 Films/Warner Bros.

Zambrano, B. (1999) Solas. España: Maestranza Fïlms.

Cómo citar: García Dussan, E. (2016). "Sobre la función legitimadora en Solas (Zambrano, 1999) y La gran familia española (Sánchez, 2013)”. Fotocinema. Revista científica de cine y fotografía, 12, pp. 285-309. Disponible: http://www.revistafotocinema.com/ 